\title{
An Efficient Synthesis of Arylated Pyridines from Conjugated Acetylenes and Substituted Benzylamines Catalyzed by Base
}

\author{
Mengping Guo ${ }^{1,2, *}(\mathbb{D})$, Bo Chen ${ }^{1,2}$, Qiming Zhu ${ }^{1}$, Hua Jin ${ }^{1}$, Qiuling Peng ${ }^{1}$ and Yanping Kang ${ }^{1}$ \\ 1 College of Chemistry and Bio-Engineering, Yichun University, Yichun 336000, Jiangxi, China; \\ chenbo25719@163.com (B.C.); Zhqm18@163.com (Q.Z.); 18079573672@163.com (H.J.); \\ ycxypq1@163.com (Q.P.); mkyp@sina.com (Y.K.) \\ 2 Engineering Center of Jiangxi University for Lithium Energy, Yichun University, Yichun 336000, \\ Jiangxi, China \\ * Correspondence: guomengping65@163.com; Tel.: +86-0795-320-0535
}

Received: 29 June 2017; Accepted: 29 July 2017; Published: 31 July 2017

\begin{abstract}
An efficient base-catalyzed synthesis of arylated pyridines has been disclosed. This reaction involving conjugated acetylenes and substituted benzylamines proceeded smoothly, giving rise to tri-aryl substituted pyridines which are biologically relevant compounds in good to excellent yields in $\mathrm{N}, \mathrm{N}$-dimethylformamide (DMF) under air at $140{ }^{\circ} \mathrm{C}$ with $\mathrm{K}_{2} \mathrm{CO}_{3}$ as catalyst.
\end{abstract}

Keywords: arylated pyridines; synthesis; transition-metal-free; base; catalysis

\section{Introduction}

The importance of pyridine motif comes from its unique biological activity in natural products [1-3], pharmaceutical compounds [4-8] and agrochemicals [9]. In addition, pyridine derivatives are widely applied in organometallic chemistry [10,11], catalysis [12], material science [13-15] and supramolecular chemistry [16-18]. Therefore, the more efficient synthesis of pyridine derivatives is still an important topic [19,20]. However, there are only very few examples reported on this topic: in 1974, Chalk [21] reported a new pyridine synthesis from conjugated acetylenes and substituted methylamines, leading to $51 \%$ of $2-p$-tolyl-3,6-diphenylpyridine and $38 \%$ of 2-p-tolyl-3,6-diphenylpyridine $\mathrm{N}$-oxide at $145^{\circ} \mathrm{C}$ under nitrogen with dimethylsulfoxide as solvent. In 2013, Shaand coworkers [22] disclosed a facile synthetic method for the preparation of trisubstituted pyridines with high regioselectivity through a three-component assembly strategy of arynes, isocyanides, and 3-bromo- or 3-acetoxypropynes, leading to $65 \%$ of 2-(4-fluorophenyl)-3,6-diphenylpyridine. In recent years, transition-metal-catalyzed C-C cross-coupling reaction has been applied to a diverse array of fields. Peter [3] recently reported the site-selective arylation of commercially available 2,3,5,6-tetrachloropyridine using the Suzuki-Miyaura reaction, allowing the selective synthesis of mono-, di-, tri- and tetraarylated pyridines in good to quantitative yields. In this context, based on the advantages of conjugated acetylenes, which are readily prepared by the catalytic oxidative coupling of terminal alkynes [23], studying more efficient synthesis of pyridine derivatives between conjugated acetylenes and substituted methylamines is still highly desirable and challenging.

\section{Resultsand Discussion}

Our interest in increasing the synthetic yield of arylated pyridines from conjugated acetylenes and substituted benzylamines under optimum conditions stemmed from the fact that Chalk's [24] work gave only a 70\% yield of 2,3,6-triphenylpyridine fromsolutions of 1,4-diphenylbutadiyne in benzylamine $(1: 6.13 \mathrm{mmol})$ after two to three hours at $180^{\circ} \mathrm{C}$ under nitrogen. Initially, we tested the 
reaction of 1,4-diphenylbutadiyne $1(1 \mathrm{mmol})$ and benzylamine $2(6 \mathrm{mmol})$ in DMSO at $140{ }^{\circ} \mathrm{C}$ in the presence of $\mathrm{K}_{2} \mathrm{CO}_{3}(0.5 \mathrm{mmol})$ under air. To our delight, 2,3,6-triphenylpyridine 3c was obtained in $85 \%$ isolated yield (Table 1, entry 3 ). Then, the effects of the ratio of starting materials 1:2 were examined (Table 1, entries 1-5). The yield of 3 improved to $96 \%$ with a 1:2 ratio of 1:8 or 1:10 (Table 1 , entries 1-2). This result really encouraged us and extensive exploration of the conditions was further carried out. When the reaction temperature was dropped from $120^{\circ} \mathrm{C}$ to $80{ }^{\circ} \mathrm{C}, 70 \%$ and $30 \%$ of the desired product 3 were obtained respectively (Table 1, entries 6-7). Subsequent solvent screening suggested that $N, N$-dimethylformamide (DMF) was the optimal one with 1,4-diphenylbutadiyne 1 (1 mmol) and benzylamine $2(8 \mathrm{mmol})$ catalyzed by $\mathrm{K}_{2} \mathrm{CO}_{3}(0.5 \mathrm{mmol})$, and the desired product 3 was obtained in $99 \%$ isolated yield without any byproducts at $140{ }^{\circ} \mathrm{C}$ under air. It is worth noting that the reaction could proceed without a base, also as a catalyst, rendering the desired product in $38 \%$ isolated yield (Table 1, entry 11), which demonstrated that the yield of desired product 3 depends on the catalytic activity of the base. To demonstrate the catalytic value of a variety of bases, the synthetic reactions of 2,3,6-triphenylpyridine between 1,4-diphenylbutadiyne $\mathbf{1}$ (1 mmol) and benzylamine 2 $(8 \mathrm{mmol})$ were carried out in DMF using different bases at $140{ }^{\circ} \mathrm{C}$ for $10 \mathrm{~h}$ with $0.5 \mathrm{mmol}$ catalyst loading under air (Table 1, entries 12-20). The almost quantitative yield (99\%) was obtained by using $\mathrm{K}_{2} \mathrm{CO}_{3}$ as the catalyst (Table 1, entry 8). Use of other bases, such as $\mathrm{Na}_{2} \mathrm{CO}_{3}, \mathrm{NaOH}, \mathrm{KOH}$ and $\mathrm{KHCO}_{3}$ also gave good yields (Table 1, entries 13-15, 17). Under similar reaction conditions, $\mathrm{Cs}_{2} \mathrm{CO}_{3}, \mathrm{NaF}_{\text {, }}$ $\mathrm{NaH}_{2} \mathrm{PO}_{4}, \mathrm{KH}_{2} \mathrm{PO}_{4}$ and $\mathrm{CH}_{3} \mathrm{COONa}$ afforded only moderate yield (Table 1, entries 12, 16, 18-20). These resultsindicate that $\mathrm{K}_{2} \mathrm{CO}_{3}$ is very effective in promoting the synthesis of arylated pyridines from conjugated acetylenes and substituted benzylamines under facile conditions.

Table 1. Optimization of the reaction conditions ${ }^{\text {a }}$.

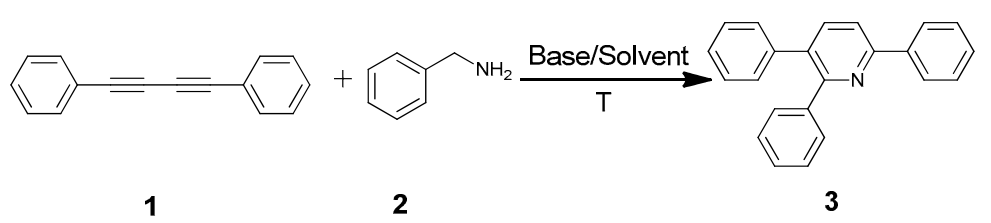

\begin{tabular}{cccccc}
\hline Entry & Ratio of 1:2 & Temperature & Solvent & Catalyst & Yield(\%) \\
\hline 1 & $1: 10$ & $140^{\circ} \mathrm{C}$ & $\mathrm{DMSO}$ & $\mathrm{K}_{2} \mathrm{CO}_{3}$ & 96 \\
2 & $1: 8$ & $140^{\circ} \mathrm{C}$ & $\mathrm{DMSO}$ & $\mathrm{K}_{2} \mathrm{CO}_{3}$ & 96 \\
3 & $1: 6$ & $140^{\circ} \mathrm{C}$ & $\mathrm{DMSO}$ & $\mathrm{K}_{2} \mathrm{CO}_{3}$ & 85 \\
4 & $1: 5$ & $140^{\circ} \mathrm{C}$ & $\mathrm{DMSO}$ & $\mathrm{K}_{2} \mathrm{CO}_{3}$ & 80 \\
5 & $1: 4$ & $140^{\circ} \mathrm{C}$ & $\mathrm{DMSO}$ & $\mathrm{K}_{2} \mathrm{CO}_{3}$ & 70 \\
6 & $1: 8$ & $120^{\circ} \mathrm{C}$ & $\mathrm{DMSO}$ & $\mathrm{K}_{2} \mathrm{CO}_{3}$ & 70 \\
7 & $1: 8$ & $80^{\circ} \mathrm{C}$ & $\mathrm{DMSO}$ & $\mathrm{K}_{2} \mathrm{CO}_{3}$ & 30 \\
8 & $1: 8$ & $140^{\circ} \mathrm{C}$ & $\mathrm{DMF}$ & $\mathrm{K}_{2} \mathrm{CO}_{3}$ & 99 \\
9 & $1: 8$ & $140^{\circ} \mathrm{C}$ & $\mathrm{DMAc}$ & $\mathrm{K}_{2} \mathrm{CO}_{3}$ & 94 \\
10 & $1: 8$ & $140^{\circ} \mathrm{C}$ & $\mathrm{PEG} 400$ & $\mathrm{~K}_{2} \mathrm{CO}_{3}$ & 50 \\
11 & $1: 8$ & $140^{\circ} \mathrm{C}$ & $\mathrm{DMF}$ & & 38 \\
12 & $1: 8$ & $140^{\circ} \mathrm{C}$ & $\mathrm{DMF}$ & $\mathrm{Cs}_{2} \mathrm{CO}_{3}$ & 65 \\
13 & $1: 8$ & $140^{\circ} \mathrm{C}$ & $\mathrm{DMF}$ & $\mathrm{Na}_{2} \mathrm{CO}_{3}$ & 81 \\
14 & $1: 8$ & $140^{\circ} \mathrm{C}$ & $\mathrm{DMF}$ & $\mathrm{NaOH}^{\circ}$ & 86 \\
15 & $1: 8$ & $140^{\circ} \mathrm{C}$ & $\mathrm{DMF}$ & $\mathrm{KOH}^{\circ}$ & 88 \\
16 & $1: 8$ & $140^{\circ} \mathrm{C}$ & $\mathrm{DMF}$ & $\mathrm{NaF}^{\circ}$ & 65 \\
17 & $1: 8$ & $140^{\circ} \mathrm{C}$ & $\mathrm{DMF}$ & $\mathrm{NaHCO}_{3}$ & 87 \\
18 & $1: 8$ & $140^{\circ} \mathrm{C}$ & $\mathrm{DMF}$ & $\mathrm{NaH}_{2} \mathrm{PO}_{4}$ & 53 \\
19 & $1: 8$ & $140^{\circ} \mathrm{C}$ & $\mathrm{DMF}$ & $\mathrm{KH}_{2} \mathrm{PO}_{4}$ & 61 \\
20 & $1: 8$ & $140^{\circ} \mathrm{C}$ & $\mathrm{DMF}$ & $\mathrm{CH}_{3} \mathrm{COONa}_{4}$ & 63
\end{tabular}

a The reactions were conducted with 1,4-diphenylbutadiyne and benzylamine, and base $(0.5 \mathrm{mmol})$, solvent $(0.5 \mathrm{~mL})$, $10 \mathrm{~h} ;{ }^{\mathrm{b}}$ Isolated yield.

Under the optimized reaction conditions, the scope of this synthetic protocol was evaluated to test the compatibility of varying symmetrical 1,4-diarylbuta-1,3-diynes as starting materials (Table 2). The 1,4-diarylbuta-1,3-diyne bearing two methyl groups at the 1- and 4-position was 
easily converted to give the desired products with excellent yield (90\%) in the synthesis of arylated pyridines using benzylamine (3cbb). However, 1,4-bis(4-butylphenyl)buta-1,3-diyne was slightly less reactive, giving the desired product with $60 \%$ yield under the same conditions, and this result clearly demonstrated that steric hindrance has an effect on the yield of desired product $(3 \mathbf{c f b})$. The reaction using sterically hindered 1,4-di-o-tolylbuta-1,3-diyne and 1,4-di-m-tolylbuta-1,3-diyne led to $77 \%$ and $78 \%$ yields, respectively $(3 \mathbf{c c b}, 3 \mathbf{c d b}$ ).Investigations of substituted benzylamines in the synthesis of arylated pyridines using 1,4-diphenylbutadiyne were also conducted. The reaction with substituted benzylamine having an electron-donating group was carried out efficiently, affording almost quantitative yield (99\%) (3cac).Various substituted benzylamines bearing electron-withdrawing groups, such as $-\mathrm{F},-\mathrm{Cl}$, and $-\mathrm{CF}_{3}$, provided the corresponding products in moderate to good yields (3cad, 3cae, 3caf). The steric and electronic effects of the substrate bearing electron-withdrawing substituent in the 3-position of benzylamine remarkably affected the reaction yield: upon using [3-(trifluoromethyl)phenyl]methanamine, product 3,6-diphenyl-2-[3-(trifluoromethyl)phenyl]pyridine was obtained in $50 \%$ yield (3caf).

Table 2. Synthesis of arylated pyridines from conjugated acetylenes and substituted benzylamines under optimized conditions. ${ }^{\text {a }}$
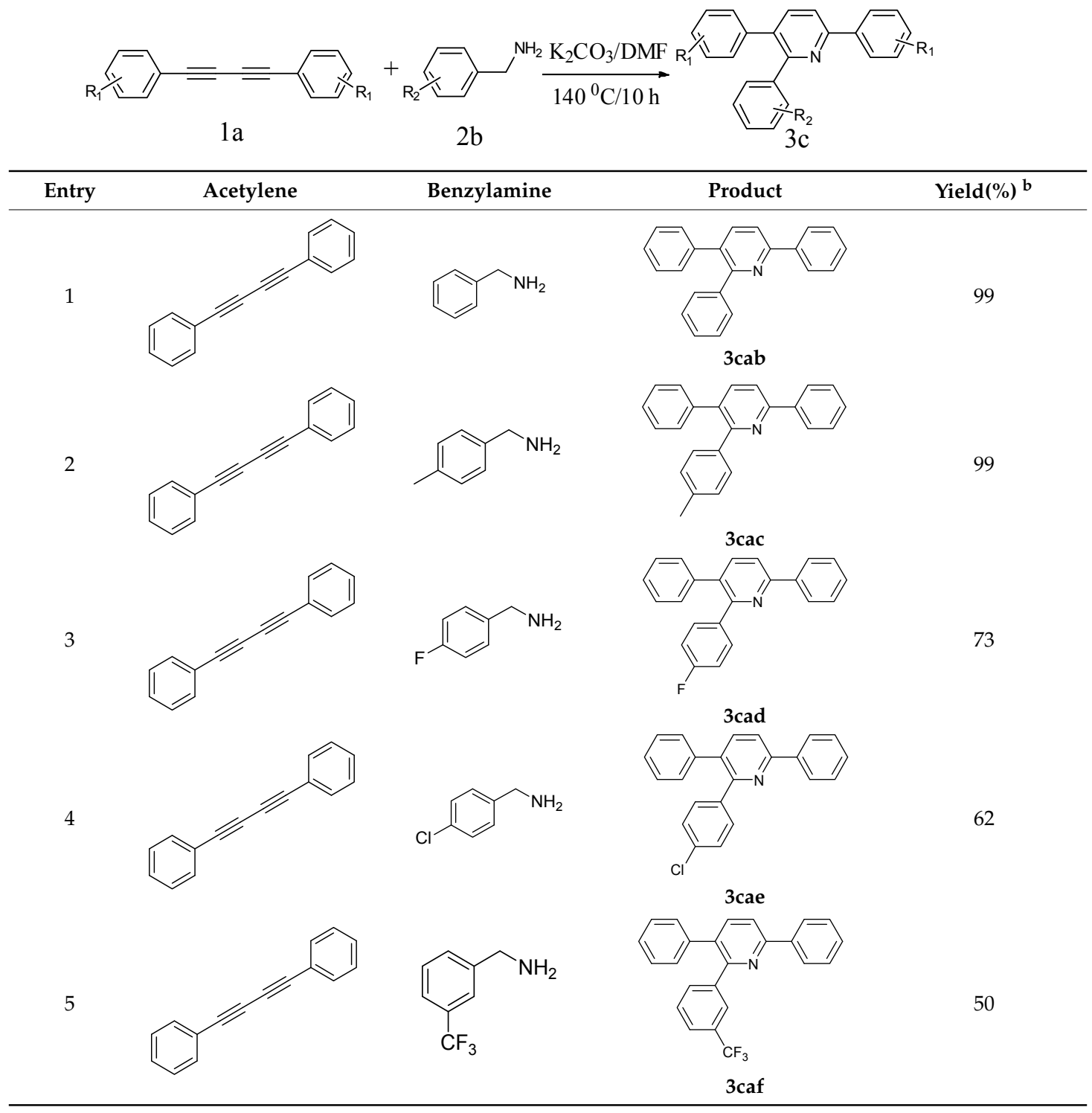
Table 2. Cont.

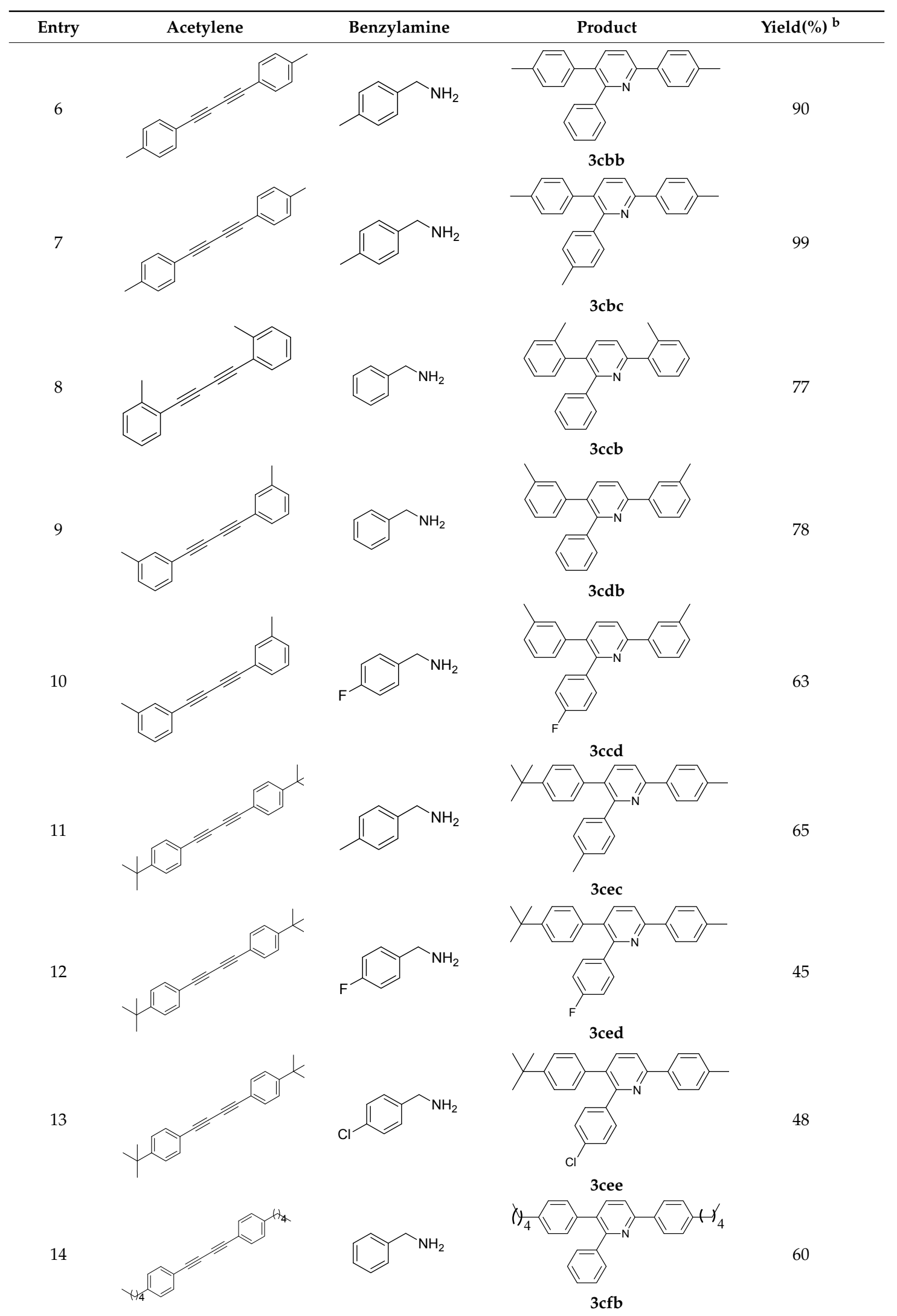

${ }^{a}$ Reaction conditions: conjugated acetylene (1a) $(0.25 \mathrm{mmol})$, substituted benzylamine (2b) $(2.0 \mathrm{mmol}), \mathrm{K}_{2} \mathrm{CO}_{3}$ $(0.5 \mathrm{mmol}), \mathrm{DMF}(0.5 \mathrm{~mL}), 140^{\circ} \mathrm{C}, 10 \mathrm{~h} ;{ }^{\mathrm{b}}$ Isolated yield. 


\section{Materials and Methods}

\subsection{General Conditions}

All manipulations were performed under air. All reagents employed in the synthesis were analytical grade, purchased from J\&K Scientific Ltd. (Shanghai, China) and used as received without any prior purification. The products were isolated by thin layer chromatography on silica gel using petroleum ether as the eluent. ${ }^{1} \mathrm{H}-\mathrm{NMR},{ }^{13} \mathrm{C}-\mathrm{NMR}$ spectra were recorded on a Bruker Avance III (400 MHz, Bruker Corporation, Billerica, MA, USA) spectrometer using tetramethylsilane as the internal standard and $\mathrm{CDCl}_{3}$ as the solvent. Chemical shift values are expressed in ppm relative to external TMS (see Supplementary).

\subsection{General Procedure for the Preparation of Arylated Pyridines}

1,4-Disubstituted-1,3-diacetylene $(0.25 \mathrm{mmol})$ and $\mathrm{K}_{2} \mathrm{CO}_{3}(0.5 \mathrm{mmol})$ were added, under air, to a solution of appropriate benzylamine $(2.0 \mathrm{mmol})$ in DMSO $(0.5 \mathrm{~mL})$ previously heated at $140{ }^{\circ} \mathrm{C}$. The resulting solution was stirred for $10 \mathrm{~h}$ at this temperature and washed with saturated aqNaCl, extracted with ethyl acetate $(3 \times 15 \mathrm{~mL})$. The combined organic phase was dried with anhydrous $\mathrm{Na}_{2} \mathrm{SO}_{4}$, filtrated and concentrated under vacuum to yield the crude product. The crude product was purified by thin layer chromatography on silica gel with petroleum ether as eluent.

\subsection{Analytical Data of Representative Products}

2,3,6-Triphenylpyridine: White crystals (m.p. $=110-111{ }^{\circ} \mathrm{C}$, lit [24] 110.5-112 ${ }^{\circ} \mathrm{C}$, lit [25] 111-112 ${ }^{\circ} \mathrm{C}$ ). ${ }^{1} \mathrm{H}-\mathrm{NMR}\left(400 \mathrm{MHz}, \mathrm{CDCl}_{3}\right) \delta 8.20(\mathrm{~d}, 2 \mathrm{H}), 7.98-7.75(\mathrm{~m}, 2 \mathrm{H}), 7.50(\mathrm{dq}, 5 \mathrm{H}), 7.30(\mathrm{ddd}, 8 \mathrm{H}) .{ }^{13} \mathrm{C}-\mathrm{NMR}$ $\left(101 \mathrm{MHz}_{,} \mathrm{CDCl}_{3}\right) \delta$ 156.64, 155.68, 140.43, 140.01, 139.43, 139.10, 134.43, 130.23, 129.59, 129.01, 128.75, 128.37, 127.84, 127.18, 127.02, 118.59. lit [25]: ${ }^{1} \mathrm{H}-\mathrm{NMR}\left(400 \mathrm{MHz}, \mathrm{CDCl}_{3}\right) \delta 8.16-8.14(\mathrm{~m}, 2 \mathrm{H}), 7.78-7.77$ $(\mathrm{m}, 2 \mathrm{H}), 7.51-7.42(\mathrm{~m}, 5 \mathrm{H}), 7.30-7.21(\mathrm{~m}, 9 \mathrm{H}) ;{ }^{13} \mathrm{C}-\mathrm{NMR}\left(100 \mathrm{MHz}, \mathrm{CDCl}_{3}\right) \delta$ 156.6, 155.6, 140.4, 140.0, $139.4,139.1,134.4,130.2,129.5,129.0,128.7,128.3,127.8,127.1,127.0,118.5$. HRMS (EI) calcd. for $\mathrm{C}_{23} \mathrm{H}_{17} \mathrm{~N}: 307.1361$, found: 307.2.

2-(4-Fluorophenyl)-3,6-diphenylpyridine: White solid (m.p. $=115-117{ }^{\circ} \mathrm{C}$, lit [22] $\left.115-116{ }^{\circ} \mathrm{C}\right) .{ }^{1} \mathrm{H}-\mathrm{NMR}$ $\left(400 \mathrm{MHz}_{\mathrm{CDCl}}\right) \delta 8.19(\mathrm{~d}, 2 \mathrm{H}), 7.82(\mathrm{~d}, 2 \mathrm{H}), 7.52(\mathrm{dd}, 5 \mathrm{H}), 7.32(\mathrm{~d}, 3 \mathrm{H}), 7.27(\mathrm{~d}, 2 \mathrm{H}), 7.01(\mathrm{~d}$, 2H). ${ }^{13} \mathrm{C}-\mathrm{NMR}\left(101 \mathrm{MHz}, \mathrm{CDCl}_{3}\right) \delta 162.53\left(\mathrm{~J}_{\mathrm{C}-\mathrm{F}}=245.6 \mathrm{~Hz}\right), 155.73,155.53,139.81,139.56,138.95$, $134.31\left(J_{C-F}=4.3 \mathrm{~Hz}\right), 132.06,131.97\left(J_{C-F}=8.2 \mathrm{~Hz}\right), 129.55,129.13,128.82,128.53,127.34,126.99$, 118.70, 114.74( $\left.\mathrm{J}_{\mathrm{C}-\mathrm{F}}=21.5 \mathrm{~Hz}\right)$. lit [22]: ${ }^{1} \mathrm{H}-\mathrm{NMR}\left(400 \mathrm{MHz}, \mathrm{CDCl}_{3}\right): \delta 8.13(\mathrm{~d}, 2 \mathrm{H}), 7.77(\mathrm{~s}, 2 \mathrm{H})$, 7.51-7.42 (m, 5H), 7.31-7.29 (m, 3H), 7.22-7.20 (m, 2H), $6.94(\mathrm{t}, 2 \mathrm{H}) ;{ }^{13} \mathrm{C}-\mathrm{NMR}\left(100 \mathrm{MHz}, \mathrm{CDCl}_{3}\right): 162.5$ $\left(J_{C-F}=245.6 \mathrm{~Hz}\right), 155.7,155.5,139.8,139.5,138.9,136.4\left(J_{C-F}=4.3 \mathrm{~Hz}\right), 134.2,131.9\left(J_{C-F}=8.2 \mathrm{~Hz}\right)$, $129.5,129.0,128.7,128.4,127.2,126.9,118.6,114.7\left(J_{C-F}=21.5 \mathrm{~Hz}\right)$. HRMS (EI) calcd. for $\mathrm{C}_{23} \mathrm{H}_{16} \mathrm{FN}$ : 325.1267, found: 325.2 .

\section{Conclusions}

In summary, an efficient protocol for arylated pyridines from conjugated acetylenes and substituted benzylamines catalyzed by base was developed, which gives a much more convenient approach to obtain arylated pyridines with good to excellent yields. Compared to the approachreported by Chalk [21], the advantages of this protocol are inthe absence ofbyproduct detected by GC-MS even if the reaction was carried out in the air. Efforts to understand this reaction mechanism are in progress in our laboratory.

Supplementary Materials: Supplementary materials are available online.

Acknowledgments: This research was financially supported by the National Natural Science Foundation of China (No. 21363026), the Scientific and Technological Landing Project of Higher Education of Jiangxi Province (No. KJLD13091). 
Author Contributions: M.G. and Q.Z. conceived and designed the experiments; B.C. performed the experiments; M.G., H.J., Q.P. and Y.K. analyzed the data and contributed with different analysis tools; finally, M.G. and B.C. wrote the paper.

Conflicts of Interest: The authors declare no conflict of interest.

\section{References}

1. Michael, J.P. Quinoline, quinazoline and acridone alkaloids. Nat. Prod. Rep. 2005, 22, 627-646. [CrossRef] [PubMed]

2. Deininger, M.W.N.; Druker, B.J. Specific targeted therapy of chronic myelogenous leukemia with imatinib. Pharmacol. Rev. 2003, 55, 401-423. [PubMed]

3. Reimann, S.; Ehlers, P.; Parpart, S.; Surkus, A.; Spannenberg, A.; Langer, P. Site-selective synthesis of arylated pyridines by Suzuki-Miyaura reactions of 2,3,5,6-tetrachloropyridine. Tetrahedron 2015, 71, 5371-5384.

4. O'Hagen, D. Pyrrole, pyrrolidine, pyridine, piperidine and tropane alkaloids. Nat. Prod. Rep. 2000, 17, 435-446.

5. Cui, J.-J.; Tran-Dube, M.; Shen, H.; Nambu, M.; Kung, P.P.; Pairish, M.; Jia, L.; Meng, J.; Funk, L.; Botrous, I.; et al. Structure based drug design of crizotinib (PF-02341066), a potent and selective dual inhibitor of mesenchymal-epithelial transition factor (c-MET) kinase and Anaplastic Lymphoma Kinase (ALK). J. Med. Chem. 2011, 54, 6342-6363. [CrossRef] [PubMed]

6. Nagamitsu, T.; Sunazuka, T.; Obata, R.; Tomoda, H.; Tanaka, H.; Harigaya, Y.; Omura, S. Total synthesis of (+)-pyripyropene A. A potent, orally bioavailable inhibitor of Acyl-CoA: Cholesterol acyltransferase. J. Org. Chem. 1995, 60, 8126-8127. [CrossRef]

7. Trecourt, F.; Gervais, B.; Mallet, M.; Quéguiner, G. First synthesis of caerulomycin C. J. Org. Chem. 1996, 61, 1673-1676. [CrossRef] [PubMed]

8. Sammakia, T.; Stangeland, E.L.; Whitcomb, M.C. Total synthesis of caerulomycin C via the halogen dance reaction. Org. Lett. 2002, 4, 2385-2388. [CrossRef] [PubMed]

9. Matolcsy, G. Pesticide Chemistry; Elsevier: Amsterdam, The Netherlands, 1988; p. 427.

10. Sweetman, B.A.; Muller-Bunz, H.; Guiry, P.J. Synthesis, resolution and racemisation studies of new tridentate ligands for asymmetric catalysis. Tetrahedron Lett. 2005, 46, 4643-4646. [CrossRef]

11. Durola, F.; Sauvage, J.P.; Wenger, O.S. Sterically non-hindering endocyclic ligands of the bi-isoquinoline family. Chem. Commun. 2006, 171-173. [CrossRef] [PubMed]

12. Verma, A.K.; Jha, R.R.; Chaudhary, R.; Tiwari, R.K.; Danodia, A.K. 2-(1-Benzotriazolyl)pyridine: A robust bidentate ligand for the palladium-catalyzed CC (Suzuki, Heck, Fujiwara Moritani, Sonogashira), CN and CS coupling reactions. Adv. Synth. Catal. 2013, 355, 421-438. [CrossRef]

13. Zhou, G.; Wong, W.-Y.; Yang, X. New design tactics in OLEDs using functionalized 2-phenylpyridine-type cyclometalates of iridium (III) and platinum (II). Chemistry 2011, 6, 1706-1719.

14. Cowley, M.J.; Adams, R.W.; Atkinson, K.D.; Cockett, M.C.R.; Duckett, S.B.; Green, G.G.R.; Lohamn, J.A.B.; Kerssebaum, R.; Kilgour, D.; Mewis, R.E. Iridium N-Heterocyclic carbene complexes as efficient catalysts for magnetization transfer from para-hydrogen. J. Am. Chem. Soc. 2011, 133, 6134-6137. [CrossRef] [PubMed]

15. Thomas, A. Functional materials: From hard to soft porous frameworks. Angew. Chem. Int. Ed. 2010, 49, 8328-8344. [CrossRef] [PubMed]

16. Wise, M.D.; Ruggi, A.; Pascu, M.; Scopelliti, R.; Severin, K. Clathrochelate-based Bipyridyl Ligands of Nanoscale Dimensions: Easy-to-access building blocks for supramolecular chemistry. Chem. Sci. 2013, 4, 1658-1662. [CrossRef]

17. Wu, D.; Zhi, L.; Bodwell, G.J.; Cui, G.; Tsao, N.; Müllen, K. Self-assembly of positively charged discotic PAHs: From nanofibers to nanotubes. Angew. Chem. Int. Ed. 2007, 46, 5417-5420. [CrossRef] [PubMed]

18. Wang, J.-L.; Li, X.-P.; Lu, X.-C.; Hsieh, I.-F.; Cao, Y.; Moorefield, C.N.; Wesdemiotis, C.; Cheng, S.Z.D.; Newkome, G.R. Stoichiometric self-assembly of shape-persistent 2D complexes: A facile route to a symmetric supramacromolecular spoked wheel. J. Am. Chem. Soc. 2011, 133, 11450-11453. [CrossRef] [PubMed]

19. Wei, Y.; Naohiko, Y. Modular pyridine synthesis from oximes and enals through synergistic copper/iminium catalysis. J. Am. Chem. Soc. 2013, 135, 3756-3759. [CrossRef] [PubMed]

20. Mohammad, M.; Matthew, D.-H.; Omar, K.-A. Direct synthesis of pyridine derivatives. J. Am. Chem. Soc. 2007, 129, 10096-10097. 
21. Chalk, A.J. A new pyridine synthesis from conjugated acetylenes and substituted methylamines. Tetrahedron 1974, 30, 1387-1391. [CrossRef]

22. Sha, F.; Shen, H.; Wu, X.Y. Highly regioselective assembly of Di- or trisubstituted pyridines fromarynes, isocyanides, and 3-bromo- or 3-acetoxypropynes. Eur. J. Org. Chem. 2013, 2013, 2537-2540. [CrossRef]

23. Chen, B.; Guo, M.-P.; Wen, Y.-J.; Shen, X.-L.; Zhou, X.-L.; Lv, M.-Y. Efficient P, O chelate palladium (II) / $\mathrm{AgNO}_{3}$ cocatalyzed homocoupling of aromatic terminal alkynes in aqueous media under ambient atmosphere. Phosphorus Sulfur Silicon Relat. Elem. 2017, 192, 259-263. [CrossRef]

24. Chalk, A.J. A new pyridine synthesis and its redirection to a pyrrole synthesis with cuprous chloride. Tetrahedron Lett. 1972, 33, 3487-3490. [CrossRef]

25. Jiang, Y.-J.; Park, C.M.; Loh, T.P. Transition-metal-free synthesis of substituted pyridines via ring expansion of 2-Allyl-2H-azirines. Organ. Lett. 2014, 16, 3432-3435. [CrossRef] [PubMed]

Sample Availability: Samples of the compounds are available from the authors.

(C) 2017 by the authors. Licensee MDPI, Basel, Switzerland. This article is an open access article distributed under the terms and conditions of the Creative Commons Attribution (CC BY) license (http://creativecommons.org/licenses/by/4.0/). 